\title{
The Investigation of the Chronical Effects of Static Flexibility Exercises on Some Biomotoric and Physiological Parameters
}

\author{
Erkan Çetinkaya \\ Correspondence: Erkan Çetinkaya, Adnan Menderes University, Faculty of Sport Science, Aydın, Turkey.
}

Received: December 3, 2018

Accepted: December 25, 2018 Online Published: December 29, 2018

doi:10.11114/jets.v7i1.3918

URL: https://doi.org/10.11114/jets.v7i1.3918

\begin{abstract}
The aim of this study was to investigate the chronical effects of static flexibility exercises on some biomotoric and physiological parameters in the students studying in sports high schools. A total of 130 high school students, 50 of whom were female and 80 of whom were male, who were studying at İncirliova Sports High School between $9^{\text {th }}$ and $12^{\text {th }}$ grades, with a mean age of $15.92 \pm 1.14$, a mean sports age of $7.05 \pm 3.54$, a mean body weight of $58.05 \pm 9.11$ kilograms, and a mean height of $1.69 \pm 0.07$ centimeters participated in the study. The participants were given training on static flexibility application with pre-tests. In order to determine the chronical effect, the participants were applied a series of tests including handgrip, sit and reach flexibility, 30 seconds push-up, static balance, vertical jump and back-leg strength tests before and after the 10-week application. The data obtained from the pre-test and post-test applications performed so as to determine the motoric characteristics of the students participating in the study was evaluated by SPSS 22.0 Package Program with a significance level of 0.05 in the $95 \%$ confidence interval. Whether the data showed normal distribution was tested by Kolmogorov-Smirnov Test. Paired Sample T-test was used to test the significance of the difference between the arithmetic means of the two related groups. The frequency distributions of the students were determined in terms of gender and class levels. The minimum, maximum, mean, standard deviation and median values of the students were calculated in terms of age (year), sports age (year), body weight $(\mathrm{kg})$, length $(\mathrm{cm})$, and Body Mass Index (BMI). It was found that there were significant differences between the pre-test and post-test results applied to determine the motoric characteristics of the students $(\mathrm{p}<0.05)$. It was revealed that the post-test results of the students in terms of sit and reach flexibility and static balance performances were better than their related pre-test results. However, no significant differences were found between the pre-test and post-test results of the students in terms of back-leg strength, handgrip, push-up and vertical jump performances ( $p>0.05$ ).It was determined that the 10-week static flexibility training (protocol) given to sports high school students before applied sports classes had positive effects on some biomotoric and physiological parameters.
\end{abstract}

Keywords: static flexibility, balance, flexibility, bouncing

\section{Introduction}

Today, whether it is a sports activity for health, a performance sport or a sport-oriented training, the first activity that we encounter is warm-up. Warm-up activities are considered as the activities performed in order to be able to get better efficiency from the athletes, be avoided from possible injuries and with the loading exercises to be done, prepare the athletes and let them adapt themselves in the most appropriate way both physiologically and psychologically (Köse, 2014).

In all kinds of sports activities, warm-up and correspondingly static stretching and dynamic exercise movements are also widely used and in both trainings and competitions, the main activity begins after all these exercises are done. In other words, in the trainings, the next section of the training begins after the warm-up and correspondingly static stretching and dynamic exercise movements are performed, and in the competitions, the competition begins after the warm-up, static stretching and dynamic exercise movements are performed (Ünlü, S., 2008).

In the studies conducted, it was stated that the static stretching activities before exercise would increase the posture, decrease the risk of injury and provide a good performance improvement. Therefore, it was expressed that static stretching movements were generally accepted forms of warming up for both children and adults. However, the findings of some scientific studies carried out on adult individuals indicated that acute static stretching exercises had a negative effect on the types of performance in which achievement depended on maximal strength improvement. On the other hand, although some authors had some concerns about the effect of dynamic exercises on the improvement of flexibility, 
dynamic warm-up movements from low to moderate intensity were suggested to be an alternative to static stretching exercises in both adults and children (Köse, 2014).

The most important factor that enables the movement of the human organism in a regular, planned and programmed manner is sports. Concordantly, the importance given to sports and the demand for it have been increasing. Today, sports is considered and performed in two frameworks as the sporting activity performed for health or for performance. Sporting activity performed for health is mostly amateur and non-regular, with more minimum feedback consideration. Today, whether it is a sports activity performed for health, a performance sport or a sport-oriented training, the first activity to be performed in a competition or training period is warm-up. The first objective in warm-up is to increase the internal temperature of the body, especially the muscles. In the sports activities begun without a good warm-up, the bloodstream of the body decreases as a result of the fact that the vessels are constricted as the body temperature decreases below $37^{\circ} \mathrm{C}$, and tendon breaks can be experienced, which can cause major injuries. For this reason, good warm-up exercises can minimize the number of injuries that may be experienced within the organism. The fact that the muscle temperature can rise up to $43^{\circ} \mathrm{C}$ while the body temperature rises up to $41^{\circ} \mathrm{C}$ during intensive exercise is the proof of how systematic our body works. This is another proof of how important warm-up before activity is (Aydın, 2017).

The most important and indispensable part of training and competition is warm-up. Warm-up activities are considered as the activities performed in order to be able to get better efficiency from the athletes, be avoided from possible injuries and with the loading exercises to be done, prepare the athletes and let them adapt themselves in the most appropriate way both physiologically and psychologically. Many trainers and athletes have the belief based on their observations and experiences that warm-up, stretching and massage done before beginning sports activities and exercises are beneficial to the body. Because of the fact that stretching exercises are one of the forms of warming up for the participation and preparation to sports, the effects of these exercises on sports performance has been an important consideration for trainers and athletes. It is stated that warm-up and stretching exercises are considered as a means of preparing musculoskeletal systems of the athletes for activity before beginning the physical activity and that they are also an important part of fitness and exercise warm-ups due to their possible effects on injury and performance. There are studies supporting that stretching exercises done by using static, dynamic or PNF stretching techniques have positive effects on increasing joint mobility, which leads to a decrease in muscle injuries and a better sports performance. It is believed that with increased muscle flexibility, performance will increase and risk of injury during severe exercises can be decreased (Songur, 2015).

\section{Stretching Exercises}

The science that deals with the forces influencing biological systems and the consequences of the effects of these forces is known as biomechanics. Biomechanical principles are noteworthy for sports trainings, especially in terms of stretching. For the stretching exercises to be effective, they must be done in accordance with biomechanical principles. The muscles are formed of ligaments. The ligaments are formed of collagens and other tendons. The ligaments have viscoelastic characteristics and allows the tissue to stretch. The viscous component allows plastic stretching, which results in a permanent streching of the tissue after the load causing distension is removed. Elastic component causes elastic stretching and the tissue returns to its previous length after the force applied is removed. One of the main characteristics of the deformation of the viscoelastic tissues is that the deformation is time-dependent. In other words, when the load is quickly applied at once, the deformation will be elastic and the tissue will immediately be reverted. If the load is applied for a period of time (stretching and holding), the deformation will be viscous and the tissue will slowly be reverted. Stretching exercises stimulate neural activities and cause a stretching in the muscle length and an increase in the range of motion of the joints. For this purpose, it is necessary to apply stretching exercises beyond the normal limits to various tissues, initially to the connective tissue. Quick and late effects are observed in the stretching exercises. Stretching exercises ensure muscle flexibility and range of motion of the joint in a very short period of time and maintain its beneficial effect for a long time. Rapid effects can be explained by the viscoelastic response of the muscle and these effects last for an hour. As a result of the stretching that lasts for 30 seconds with four five times of repetition, it is observed that the muscle viscoelasticity decreases, the length of the muscle-tendon unit stretches, the tension tolerance decreases, and the range of motion of the joints increases. It is usually experienced in the PNF stretching technique that there is more increase in the range of motion of the joints compared to static and ballistic stretching (Çelebi, M., 2017).

\section{Stretching Techniques Used in Improving Flexibility}

Stretching can be defined as the movement applied by the external and internal force to increase the range of motion of the joints.

\section{Dynamic Stretching Technique}

Dynamic elasticity is the ability of the muscles to perform the movements dynamically by keeping the extremities at the limits of the range of motion of their joints. 


\section{Static Stretching Technique}

The fact that the extremities can be kept at the very ultimate point without any external assistance as a result of the muscles proper functioning after the normal movement of the joint is completed in one joint can be defined as "active" unassisted static stretching. For example; lifting the leg up and holding it at that point without any external assistance. The fact that the practitioner can hold the extremity at the ultimate point with the assistance of the body weight, the assistance of an extremity or an external assistance like a chair etc. can be defined as "passive" assisted static stretching.

\section{P.N.F. Stretching Technique}

PNF stretching techniques involve the passively stretching of a muscle group first, the isometric contraction of them against the resistance in the stretched position then, and the passively stretching again until the limit of the range of motion. In PNF stretching, an assistant is often used to provide the resistance to isometric contraction and to reach the limit of the range of motion in the last passive stretching (Çatal, M., 2011).

\section{Physiological and Psychological Effects of Warm-up on the Organism}

The main purpose of warm-up is to accelerate the blood circulation by slowly increasing the number of heart beats. This physiological change experienced increases the body temperature and enables the blood and oxygen to increase with circulation, which is necessary for the muscles to be prepared for the physical activity of the body. The muscles and tendons are prepared for the movement, become more flexible and thus, the risk of injury is reduced. All these contribute to the improvement of the performance. In many scientific studies, it could be seen that body temperature and metabolic rate increased by $13 \%$ after optimal warm-up. The most appropriate body temperature to be able to apply the sports applications in the desired effectivity is between $38.5^{\circ} \mathrm{C}-39^{\circ} \mathrm{C}$. At the appropriate body temperature, the rate of metabolic activities in the organism increases by $13 \%$. High and optimal temperature applies the functions of the central nervous system faster, and thus, the rate of reaction and contraction increases. Muscle viscosity decreases in this warm environment. The chemical reactions of the contraction and recovery occur more rapidly. The rise of the body temperature by $2^{\circ} \mathrm{C}$ increases the rate of contraction by about $20 \%$. It is possible to prevent the injuries that may be experienced in the organism with well-applied warm-up exercises. With the warm-up, the flexibility-oriented injuries that may be experienced in the muscles, chordases, ligaments, cartilage tissue and skin can be prevented. The range of motion of the joints increases in the athletes in time. Not only does this help to perform the technique better but it also helps to reduce injuries.

When the psychological effects of warm-up are examined, it can be said that warm-up also involves mentally focusing on the training or competition. During the warm-up period, the athlete must have the aim of demonstrating the best performance by concentrating on the exercise done according to the content of the training. In the cases when adequate warm-up is not performed, a general looseness in the behavior, laziness, joylessness, boredom from exercise, fatigue without a reason, lack of expression, lack of initiation, weakness of will power may arise. The athlete cannot prompt and use the existing power, cannot run and compete. While preparing his body for the competition or training with light exercises, he must also ask himself what he will achieve as a result of this training or competition and by what ways and strategies he can obtain these achievements, and he must be motivated in accordance with the answers on his mind. Warm-up is the time when the athlete can speak to himself most. The fact that these conversations are positive effects the performance in the good way. He must repeat the expression "I can do it" continuously and believe in it. Afterwards, he must forget everything else but focus on the race strategy, technical applications, and the competition or the training track. A very well-motivated athlete can achieve far beyond of what he can actually do (Tümer, 2015).

\section{Warm-up and Motoric Adaptation}

Due to the creation characteristics of human, his motor characteristics vary according to the organism's adaptability and level of efficiency. With the warm-up during an activity, it is aimed to reach the optimal reaction ability and coordination capability. In short, warm-up exercises prepare the organism for intensive exercises in the light of many internal and external factors. This preparation should be considered as motoric, physiological and psychological adjustment and it should be aimed to prevent the athlete from possible injuries by taking the optimum efficiency from the activity (Aydın, 2017).

\section{Method}

\subsection{Participants}

A total of 130 high school students, 50 of whom were female and 80 of whom were male, who were studying at İncirliova Sports High School between $9^{\text {th }}$ and $12^{\text {th }}$ grades, with a mean age of $15.92 \pm 1.14$, a mean sports age of $7.05 \pm 3.54$, a mean body weight of $58.05 \pm 9.11$ kilograms, and a mean length of $1.69 \pm 0.07$ centimeters participated in the study. The participants were given training on static flexibility application with pre-tests. In order to determine the chronical effect, the participants were applied a series of tests including handgrip, sit and reach flexibility, 30 seconds push up, static balance, vertical jump and back-leg strength tests before and after the 10-week application. 


\subsection{Static Flexibility Exercise Application}

The content of the study was explained to the participant students in detail before the pre-test measurements. Besides, all the participants were warned not to do exercise heavily on the day before the measurement. First, height and weight measurements of the students were taken and then they were made to do a 5-minute warm-up run. After the testing measurements that were made to ensure adjustment, performance-oriented pre-test values were applied and taken as handgrip, back-leg strength, vertical jump, sit-reach flexibility, and static balance tests. The students studying at İncirliova Sports High School were applied a 10-week static flexibility exercises based on the literature in order to determine the chronical effect of static flexibility exercises. In her study, Gülsün Aydın (2011) stated that the most effective duration of static flexibility for healthy individuals was 15-30 seconds according to literature and that the American College of Sports Medicine (ACSM) flexibility program for a general physical appropriateness program ought to be composed of 10-30 seconds of periods, with three-four sets a day and two-three days a week (Aydın, 2011).

In the applied sports classes that were composed of two lessons (80 minutes) which varied 3 to 5 days, the students studying at Incirliova Sports High School were applied static flexibility exercises in accordance with the application protocols based on literature; beginning with a 5-minute warm-up run, which was followed by a set of movements, 30 seconds of practice, 15 seconds of rest, with three repetitions. Static flexibility exercises were applied for a total of 10-week period directed to five lower extremities and one upper extremity muscle group; the lower extremity muscle groups for plantar flexors, hip extensors, hamstrings, hip flexors, quadriceps femoris, and the upper extremity for triceps surae muscle groups. At the end of 10 weeks, post-tests were applied to determine the chronic effects of static flexibility exercises and the study was concluded.

\subsection{Data Collection Tools}

Age: By checking from their National ID Cards, the ages of the participants were determined as date, month, year.

The Measurement of Height: The measurement was made when the participants were wearing shorts. During the measurement of height, the participants were barefoot, the heels were adjoint, the body and head were upright, and their eyes were looking across. The participants were made to free their arms on both sides. The horizontal axis was made to contact the head of the subject and the closest value was recorded as height in centimeters. The tool with a precision degree of $0.1 \mathrm{~m}$ (Harpender Anthropometer, Holtain Ltd.) was used for the measurement of height (Aydın, 2017).

The Measurement of Body Weight: During the measurement, the participants were made to be barefoot and wear clothes that would not affect the weight. While the measurement was being made, the participants were made to stand on the weighing tool with equal feet. The measurements were made while the participants were standing upright and still. The body weight measurements of the participants were made by an electronic weighing took with a precision degree of \pm 100 gr. (Tanita TBF 401 A, Japan). The value obtained was saved in kilograms (Tamer, 2000).

Body Mass Index = Body weight $(\mathrm{kg}) /$ Height $\left(\mathrm{cm}^{2}\right)$.

Body Mass Index values of all the participants were obtained by squaring the height and dividing it to body weight (Sevimli, 2008).

Handgrip Power Test: The test was performed by a Takei Grip-D (Japan) hand dynamometer which measures a power of 0-100 kg. The dynamometer was adjusted in accordance with the hand size of the research group. The measurements were made while the participants in the research group were standing, swinging their arms down, pressing the dynamometer with maximum force without any contact with the body. Two separate measurements were made for the right and left hand and the best value was determined in kg. (Şahin et al., 2012).

Vertical Jump Test: The test measures the participants' vertical jump achievement. The measurements of the participants were made by Takei Physical Fitness Test Vertical Jump-meter. The participants stepped on the rubber part of the jump-meter and the measuring part of the jump-meter was tied to their waists at the same time. The rope of the jump-meter was strained and with the help of their arms, the participants performed vertical jumps and they were digitally measured and recorded in the computer (Uluçay, 2009).

Sit and Reach Flexibility Test: For this test, the participants were asked to sit on the floor barefoot, put their soles on the test table, and slowly push the ruler on the test table forward without bending their knees and wait for 1-2 seconds at the farthest point they can reach. The test was repeated three times for each participant and the highest value was recorded in $\mathrm{cm}$ (Aydin, 2017).

The Measurement of Back Strength: The measurement was performed by using Takei back and leg dynamometer. After five minutes of warm-up, the athletes placed their feet on the dynamometer table with their knees tight, and then lifted the dynamometer bar vertically upwards at the maximum level with their arms tight, their backs straight and the body slightly bent forward. This lifting was repeated three times and the best value of each subject was recorded. 
The Measurement of Leg Strength: The measurement was performed by using Takei back and leg dynamometer. After five minutes of warm-up, the athletes placed their feet on the dynamometer table with their knees bent, and then lifted the dynamometer bar vertically upwards at the maximum level by using their legs, with their arms tight, their backs straight and the body slightly bent forward. This lifting was repeated three times and the best value of each subject was recorded (Akbal, 1998).

\subsection{Static Balance}

Flamingo Balance Test: Flamingo Balance Test was used to determine the static balances of the participants. According to this test, the participant subject stood on the $50 \mathrm{~cm}$ long, $4 \mathrm{~cm}$ high and $3 \mathrm{~cm}$ wide wooden balance beam with his dominant foot. He bent the other foot from the knee, pulled it towards his hip, and held it with his hand on the same side. While the participant was balanced in this way with one foot, the time was started and he tried to remain in balance for one minute. When the participant became unbalanced (if he left while holding his foot, if he fell from the board, if he touched the floor with any part of his body, etc.), the time was stopped. When the participant stood on the balance beam again and stayed balanced, the time continued again from where it was paused. The test continued for one minute like that. At the end of the time period, the participant's each attempt to stay balanced was counted (after falling) and this number was recorded as the participant's static balance score at the end of the test (Tanır, 2018).

Push-up Test: 1/1000 precision hand stopwatch were used for $30 \mathrm{sec}$. push-up test. At the starting position, hands are directly under the shoulders or slightly wider. Elbows are straight form without touching the ground and knees stretched. Push-up was performed while the body weight is on the arms and ends of the feet. In the Push-up test, the number of push-up done was evaluated by counting for 30 seconds (Taşkın et al., 2015).

\subsection{Data Analysis}

The data obtained from the pre-test and post-test applications performed so as to determine the motoric characteristics of the students participating in the study was evaluated by SPSS 22.0 Package Program with a significance level of 0.05 in the $95 \%$ confidence interval. Whether the data showed normal distribution was tested by Kolmogorov-Smirnov Test. Paired Sample T-test was used to test the significance of the difference between the arithmetic means of the two related groups. The frequency distributions of the students were determined in terms of gender and class levels. The minimum, maximum, mean, standard deviation and median values of the students were calculated in terms of age (year), sports age (year), body weight $(\mathrm{kg})$, length $(\mathrm{cm})$, and Body Mass Index (BMI).

\section{Results}

Table 1. Frequency Distribution of the Students in Terms of Gender and Class Levels

\begin{tabular}{|c|c|c|c|c|c|}
\hline \multirow{3}{*}{ Class Levels } & \multicolumn{4}{|c|}{ Gender } & \multirow{3}{*}{ Total } \\
\hline & \multicolumn{2}{|c|}{ Female } & \multicolumn{2}{|c|}{ Male } & \\
\hline & $N$ & $\%$ & $N$ & $\%$ & \\
\hline 9. grade & 15 & 30.0 & 21 & 26.3 & 36 \\
\hline 10. grade & 20 & 40.0 & 20 & 25.0 & 40 \\
\hline 11. grade & 12 & 24.0 & 25 & 31.3 & 37 \\
\hline 12. grade & 3 & 6.0 & 14 & 17.5 & 17 \\
\hline
\end{tabular}

According to Table 1 , of the 130 students who participated in the research, 36 of them ( $n=15$ female and 21 male) were studying in the $9^{\text {th }}$ grade, 40 of them $\left(\mathrm{n}=20\right.$ female and 20 male) were studying in the $10^{\text {th }}$ grade, 37 of them $(n=12$ female and $n=25$ male) were studying in the $11^{\text {th }}$ grade, and 17 of them $\left(n=3\right.$ female and 14 male) were studying in the $12^{\text {th }}$ grade.

Table 2. Descriptive Statistics in Terms of the Students Who Participated in the Research

\begin{tabular}{lccccc}
\hline Variables & Minimum & Maximum & $\mathbf{X}$ & Sd \pm & Median \\
\hline Age (year) & 14 & 18 & 15.92 & 1.14 & 16 \\
Training age (year) & 1 & 10 & 7.05 & 3.54 & 6 \\
Height (cm.) & 1.54 & 1.93 & 1.69 & 0.07 & 1.70 \\
Weight $(\mathrm{kg})$. & 40 & 88 & 58.05 & 9.11 & 56.00 \\
Body Mass Index $\left(\mathrm{kg} / \mathrm{cm}^{2}\right)$ & 15.06 & 26.33 & 20.07 & 2.15 & 19.77 \\
\hline
\end{tabular}

In Table 2, it could be seen that the students who participated in the research were between the range of 14-18 years of age (age=15.92 \pm 1.14 ). The sports age of the students ranged between 1-10 years (sports age $=7.05 \pm 3.54$ ). Of the students whose height ranged between $1.54-1.93 \mathrm{~cm}$ (height $=1.69 \pm 0.07$ ) and whose body weight mean was $58.05 \pm 9.11$ $\mathrm{kg}$, the weakest was $40 \mathrm{~kg}$ and the fattest was $88 \mathrm{~kg}$. The students' BMI values ranged between $15.06-26.33 \mathrm{~kg} / \mathrm{cm}^{2}$ $(\mathrm{BMI}=20.07 \pm 2.15)$. 
Table 3. The Comparison of the Students' Pre-test and Post-test Scores

\begin{tabular}{|c|c|c|c|c|c|c|c|c|}
\hline \multirow{2}{*}{ Variables } & \multicolumn{3}{|c|}{ Pre-test } & \multicolumn{3}{|c|}{ Post-test } & \multirow{2}{*}{$\mathbf{t}$} & \multirow[b]{2}{*}{$\mathbf{p}$} \\
\hline & $N$ & $\mathbf{X}$ & Sd \pm & $N$ & $\mathbf{X}$ & $\mathbf{S d} \pm$ & & \\
\hline Right Handgrip strength $\mathrm{N} / \mathrm{kg}$ & 130 & 34.05 & 9.18 & 130 & 34.94 & 9.11 & -1.350 & 0.179 \\
\hline Left Handgrip strength $N / \mathrm{kg}$ & 130 & 32.96 & 9.01 & 130 & 33.13 & 8.68 & -0.247 & 0.805 \\
\hline Back Strength & 130 & 99.72 & 31.16 & 130 & 100.53 & 27.95 & -0.344 & 0.731 \\
\hline Leg Strength & 130 & 104.57 & 38.12 & 130 & 110.50 & 36.21 & -1.766 & 0.080 \\
\hline Vertical Jump (cm) & 130 & 48.37 & 19.90 & 130 & 46.72 & 11.09 & 0.941 & 0.348 \\
\hline Push-up (sec.) & 130 & 22.82 & 10.20 & 130 & 21.43 & 12.32 & 1.259 & 0.210 \\
\hline Sit and reach $(\mathrm{cm})$ & 130 & 32.85 & 7.88 & 130 & 34.73 & 8.76 & -2.914 & $0.028 *$ \\
\hline Flamingo Balance Test & 130 & 3.27 & 4.54 & 130 & 1.86 & 3.06 & 3.283 & $0.001 *$ \\
\hline
\end{tabular}

According to Table 3, it was found that there were significant differences between the pre-test and post-test scores of the students which were performed in order to determine their motoric characteristics $(\mathrm{p}<0.05)$. It was understood that the post-test scores of the students in terms of the flexibility and static balance performances were better than their pre-test scores. However, no significant differences were found between the pre-test and post-test scores of the students in terms of right hand and left handgrip strength, back strength, leg strength, and push-up and vertical jump performances $(\mathrm{p}>0.05)$.

\section{Discussion}

The study was carried out in order to investigate the effects of static flexibility exercises on some biomotoric and physiological parameters in the students studying in sports high schools. A total of 130 high school students, 50 of whom were female and 80 of whom were male, who were studying at İncirliova Sports High School between $9^{\text {th }}$ and $12^{\text {th }}$ grades, with a mean age of $15.92 \pm 1.14$, a mean sports age of $7.05 \pm 3.54$, a mean body weight of $58.05 \pm 9.11$ kilograms, and a mean height of $1.69 \pm 0.07$ centimeters participated in the study. Discussion and evaluation were made in terms of the variables on the basis of scientific data.

In their study, Bazett-Jones et al. (2008) reported that the results of the 6-week static flexibility program had no chronic effect on the speed or vertical jump performance (Bazett-Jones, Gibson, \& McBride, 2008).

In the study by Noóbrega, A. et al. (2005), they investigated the interaction between resistance training and flexibility training in healthy young adults and it was revealed after the 12-week training program applied on four different groups that the pre-test and post-test values of the right and left handgrip, and bench-press did not show any significance but there was an increase in the leg-press (kg) performance values (Noóbrega, A. et al., 2005).

In the study by Woolstenhulme et al. (2006), they defined the sample group as control, ballistic stretching, sprint and static stretching, and they stated that the flexibility (sit and reach) values increased significantly in all other groups compared to the control group after the 6-week stretching exercises. In their study based on the hypothesis that the 6-week stretching exercises could reduce vertical jump, they reported that, unlike their hypothesis, flexibility exercises did not have any effect on the vertical jump height of the participants (Woolstenhulme et al., 2006).

On the other hand, Kokkonen et al. (2007) reported an increase in the jumping performances of the participants as a result of the 10-week static flexibility exercise program on the individuals that were non-athletes (Kokkonen et al., 2007).

Baydemir and Alp (2018), found that specific training for football players had a positive effect on balance performance (Baydemir \& Alp, 2018).

In another study conducted by Gelen et al. (2008), there were research results indicating that static stretching application after general warm-up had a negative effect on the vertical jump (Gelen et al., 2008).

Çoknaz et al. (2008) conducted a research indicating that static flexibility exercises did not have any effect on the vertical jump performance (Çoknaz et al., 2008).

In the study by Yaman et al. (2004) which investigated the effect of 10-week static flexibility exercise on the university students' flexibility and body fat percentage, it was revealed that while there was an increase in the flexibility values of the females, there was a decrease in their body fat percentage values. However, they stated that these results were not statistically significant (Yaman et al., 2004).

Aydin (2011) reported in his doctoral dissertation that there was an increase in the range of motion of the knee joint and the flexibility performances, and a decrease in the speed and jump performances according to long term static flexibility exercises acute changes (Aydın, 2011).

In their study on active individuals, Murphy et al. (2010) determined that static flexibility exercises increased the flexibility and range of motion of the knee joint (Murphy et al., 2010). 
In the study by McMillian et al. (2006), they reported that static stretching exercises decreased the power and single-repetition maximal force (McMillian et al., 2006).

In the study by Alp et al. (2018) determined that the effect of static stretching exercises applied to taekwondo after isokinetic maximal and explosive power is not significant (Alp et al.,2018).

Handrakis et al. (2010) reported in their study that static stretching improved dynamic balance (Handrakis et al., 2010).

In the study by Subasi et al. (2008), similar expressions were encountered, and they reported that both balance and position perception sense increased after warm-up (Subasi et al., 2008).

In the study conducted by Behm et al. (2004), they found that stretching exercises spoiled balance performance (Behm et al., 2004).

\section{Conclusion}

In the study that investigated the chronic effects of static stretching exercises on performance, it was concluded that the 10-week exercise protocol improved the flexibility and balance values positively, but it had no positive effects on push up, handgrip, and back-leg strength performance values. It was aimed to emphasize the importance of including static stretching in the exercise prescriptions as well as the effects of static stretching exercises on some sporting performance values. While the results obtained from this study are thought to provide valuable information for other researchers, it is also foreseen that these results can help the amateur or elite athletes and trainers in the light of scientific data.

\section{References}

Akbal, M. (1998). The Physical Effects of Exercises on The Muscular Power of Wrestlers in The Preparatory Term Training Programs, Master Thesis, Selçuk University, Institute of Health Science, Department of Physical Education and Sport, Konya.

Alp, M., Çatıkkaş, F., \& Kurt, C. (2018). Acute effects of static and dynamic stretching exercises on lower extremity isokinetic strength in taekwondo athletes. Isokinetics and Exercise Science, (Preprint), 1-5.

Aydın, G. (2011). Acute and Chronic Effects of Long Term Static Streching Exercises on Performance. Doctoral Thesis, Anadolu Üniversitesi, Institute of Health Science, Department of Physical Education and Sport, Eskişehir.

Aydın, Y. (2017). The Effects of Different Warm-Up Protocols on Some Aerobic and Anaerobic Motor Tests, Master Thesis, İönü University , Institute of Health Science, Department of Physical Education and Sport, Malatya.

Baydemir, B., \& Alp, M. (2018). The effects of specific trainings applied to 14 age male soccer players on their balance, sprint and technical skills. Journal of Education and Training Studies, 6(11), 27-31. https://doi.org/10.11114/jets.v6i11.3415

Bazett-Jones, D. M., Gibson, M. H., \& McBride, J. M. (2008). Sprint and vertical jump performances are not affected by six weeks of static hamstring stretching. The Journal of Strength \& Conditioning Research, 22(1), 25-31. https://doi.org/10.1519/JSC.0b013e31815f99a4

Behm, D. G., Bambury, A., Cahill, F., \& Power, K. (2004). Effect of acute static stretching on force, balance, reaction time, and movement time. Medicine \& Science in Sports \& Exercise, 36(8), 1397-1402. https://doi.org/10.1249/01.MSS.0000135788.23012.5F

Çatal, M., O. (2011). The Effects Of Different Streching Times On Vertical Jump Performans, Master Thesis, Karadeniz Technical University, Institute of Educational Sciences, Department of Physical Education and Sport, Trabzon.

Çelebi, M. M., \& Zergeroğlu, A. M. The Effects of Warm Ups and Stretching Exercises on Balance and Proprioception Ankara University Faculty of Medicine 70(2), 83-89.

Çoknaz, H., Yıldırım, N. Ü., \& Özengin, N. (2008). The Effects of Different Stretching Durations on Performance in Artistic Gymnast, Spormetre the Journal of Physical Education and Sport Sciences, 6(3), 151-157

Gelen, E., Saygın, Ö., Karacabey, K., \& Kılınç, F. (2008). Acute effects of static stretching on vertical jump performance in children. Journal of Human Sciences, 5(1).

Handrakis, J. P., Southard, V. N., Abreu, J. M., Aloisa, M., Doyen, M. R., Echevarria, L. M., \& Douris, P. C. (2010). Static stretching does not impair performance in active middle-aged adults. The Journal of Strength \& Conditioning Research, 24(3), 825-830. https://doi.org/10.1519/JSC.0b013e3181ad4f89

Kokkonen, J., Nelson, A. G., Eldredge, C., \& Winchester, J. B. (2007). Chronic static stretching improves exercise performance. Medicine \& Science in Sports \& Exercise, 39(10), 1825-1831.

https://doi.org/10.1249/mss.0b013e3181238a2b 
Köse, B. (2014). The Effect of Different Warm-Up Methods on Flexibility Jumping and Balance, Master Thesis, Ondokuz Mayıs University, Institute of Health Science, Department of Physical Education and Sport, Samsun.

McMillian, D. J., Moore, J. H., Hatler, B. S., \& Taylor, D. C. Dynamic vs. static-stretching warm up: the effect on power and agility performance. The Journal of Strength \& Conditioning Research, 20(3), 492-499. https://doi.org/10.1519/18205.1

Murphy, J. C., Nagle, E. F., Robertson, R. J., \& McCrory, J. L. (2010). Effect of single set dynamic and static stretching exercise on jump height in college age recreational athletes, International Journal of Exercise Science, 3(4), 214-224.

Noóbrega, A. C., Paula, K. C., \& Carvalho, A. C. G. (2005). Interaction between resistance training and flexibility training in healthy young adults. The Journal of Strength \& Conditioning Research, 19(4), 842-846. https://doi.org/10.1519/00124278-200511000-00020

Şahin, M., Saraç, H., Çoban, O., \& Coşkuner, Z. (2012). An Investigation of the Effects of Taekwondo Training on the Motor Development Levels of Children. Journal of Sports and Performance Researches-JSPR, 3(1).

Sevimli, D. (2008). Investigation of the Relationship between Body Mass Index and Physical Activity in Adults. TAF Prev Med Bull, 7(6), 523-528.

Songur, A. (2015). The Effect of Active Static Stretching and Different Rest Intervals on Isokinetic Leg Strength, Master Thesis, Gazi University ,Institute of Health Science, Department of Physical Education and Sport, Ankara.

Subasi, S. S., Gelecek, N., \& Aksakoglu, G. (2008). Effects of different warm-up periods on knee proprioception and balance in healthy young individuals. Journal of Sport Rehabilitation, 17(2), 186-205.

https://doi.org/10.1123/jsr.17.2.186

Tamer, K. (2000). Sporda fiziksel-fizyolojik performansın ölçülmesi ve değerlendirilmesi. Bağırgan Yayınevi.

Tanır, H. (2018). The effect of balance and stability workouts on the development of static and dynamic balance in 10-12-year-old soccer players. Journal of Education and Training Studies, 6(9), 132-135. https://doi.org/10.11114/jets.v6i9.3499

Taşkın, C., Karakoç, Ö., Acaroglu, E., \& Budak, C. (2015). The Investigation of the Relationship among Selected Motoric Features of Children Soccer Players. Journal of Sports and Performance Researches, 6(2), 101-107.

Tümer, M. (2015). The Effect of Different Rest Periods on Isokinetic Leg Strength After Dynamic Warm-up, Master Thesis, Gazi University, Institute of Health Science, Department of Physical Education and Sport, Ankara.

Uluçay, G. (2009). The Effect of Plyometric Trainings That Are Applied to The 12-14 Years Old Basketball Players on The Vertical Jump, Master Thesis, Trakya Üniversitesi Institute of Health Science, Department of Physical Education and Sport, Edirne.

Ünlü, S., S. (2008). The Sudden Effects of Combined Warm-up Activities to Main Aerobic Power Performances, Master Thesis, Sakarya University Insitute of Social Sciences, Department of Physical Education and Sports Teacher, Sakarya.

Woolstenhulme, M. T., Griffiths, C. M., Woolstenhulme, E. M., \& Parcell, A. C. (2006). Ballistic stretching increases flexibility and acute vertical jump height when combined with basketball activity. The Journal of Strength \& Conditioning Research, 20(4), 799-803.

Yaman, E., Kürkçü, R., Yeniçeri, M., \& Can, S. (2004). Body Fat Percentage of Static Streching Exercises in Young Women and the Influence on Elasticity, Journal of Physical Education and Sport Sciences, 6(4), 54-61.

\section{Copyrights}

Copyright for this article is retained by the author(s), with first publication rights granted to the journal.

This is an open-access article distributed under the terms and conditions of the Creative Commons Attribution license which permits unrestricted use, distribution, and reproduction in any medium, provided the original work is properly cited. 